\title{
DISPERSÃO GEOQUÍMICA NA BACIA HIDROGRÁFICA DO RIO SÃO DOMINGOS (RJ) CONTROLADO PELA MORFOLOGIA DA BACIA
}

\author{
GEOCHEMISTRY SPREAD IN SÃO DOMINGOS HYDROGRAPHIC BASIN (RJ) CONTROLLED \\ BY BASIN MORPHOLOGY
}

\author{
Ariadne Marra de SOUZA ${ }^{1}$, Mauro César GERALDES ${ }^{2}$, Ana Cristina ALMEIDA ${ }^{3}$ \\ ${ }^{1}$ Universidade Federal do Espírito Santo, Departamento de Geologia do Centro de Ciências Exatas, Naturais e da Saúde. \\ E-mail ariadnemarrasouza@gmail.com \\ ${ }^{2}$ Universidade do Estado do Rio de Janeiro. Faculdade de Geologia. mauro.geraldes@gmail.com \\ ${ }^{3}$ Pontifica Universidade Católica - Laboratório de Águas - PUC-Rio. E-mail: acmalmeida73@gmail.com

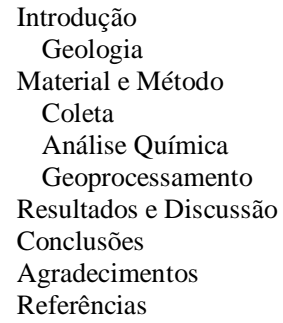

RESUMO - A bacia hidrográfica do rio São Domingos está localizada na Faixa Ribeira em uma área com forte estruturação que condiciona o sistema de drenagem. Está situada no noroeste do estado do Rio de Janeiro em uma região predominantemente agrícola, onde ocorre mudança de relevo tanto para atender esta atividade quanto decorrente do processo de desmatamento para pecuária e extração doméstica de madeira. A partir da utilização do método de análise e de concentração de metais nos sedimentos de corrente e correlação com as rochas do embasamento, foi possível identificar as diferentes influências nas concentrações de metais observadas nestes sedimentos, bem como a dispersão geoquímica. Foram observadas que as concentrações de metais $(\mathrm{Cd}, \mathrm{Co}, \mathrm{Cr}, \mathrm{Cu}, \mathrm{Ni}, \mathrm{Pb}, \mathrm{Sr}$, V e Zn) se distribuem em quatro zoneamentos morfoestruturais definidos, também, de acordo com a estruturação da drenagem e, cujas fontes foram caracterizadas como de origem antrópicas e naturais, sendo essa a mais expressiva contribuição que se origina das rochas do embasamento, intensificadas pela estruturação da drenagem através da erosão.

Palavras-chave: Meio Ambiente. Geoquímica. Sedimentos quaternários. Sistema de Drenagem.

\begin{abstract}
The São Domingos hydrographic basin are located in Ribeira Belt where are strongly structured than conditioned the drain network. It is on Rio de Janeiro state northwest that is a main farming area, when occur relief changes from crop demand like a result of deforestation process to livestock and logging. Used metals concentration in stream sediments and basement rocks correlated was possible identify different influences in metals concentrations in these sediments, as well as spread geochemistry of that. It was observed than metals concentration $(\mathrm{Cd}, \mathrm{Co}, \mathrm{Cr}, \mathrm{Cu}, \mathrm{Ni}, \mathrm{Pb}, \mathrm{Sr}, \mathrm{V}$ e $\mathrm{Zn}$ ) are distributed in four morphostructural zones, also defined by network drain structuring and whose source was characterized like anthropic and natural source. Are an anthropic contribution up hydrographic basin however, the most main contribution is coming from basement rocks in the measured concentration and, that contribution is intensify by drain structuring.
\end{abstract}

Key-words: Environment, geochemistry, Quaternary Sediments, Drain system.

\section{INTRODUÇÃO}

As modificações na morfologia natural resultam em alteração da salinidade, erosão e sedimentação de rios e encostas e, consequentemente, afeta o desenvolvimento e manutenção de ecossistemas (Villela \& Mattos, 1975 citado por Dantas, 2007). Dentre alguns dos processos causadores destas modificações, inclui-se o sistema de plantio em larga escala que, em via de regras, vem acompanhada da ampla utilização de defensivos agrícolas.

Desta forma, sendo o Brasil um grande produtor agropecuário, está entre os maiores consumidores de pesticida no mundo com significativo aumento nos últimos trinta anos
(Spadotto et al., 2001), ao qual soma-se ao processo de degradação, o mau uso dos recursos naturais (solo, água e biodiversidade), além das recorrentes modificações morfológicas e na dinâmica fluvial.

A área do estudo é a bacia hidrográfica do rio São Domingos (BHRSD), afluente do rio Muriaé, pertencente ao sistema Paraíba do Sul, localizada no nordeste do estado do Rio de Janeiro. Seus limites correspondem, em sua maioria, ao município de São José de Ubá no estado do Rio de Janeiro, sendo este um município com atividade econômica calçada na agropecuária, onde ocorre degradação dos 
recursos hídricos e das matas, predominando áreas de pastagens - 88,30\% (Fidalgo \& Abreu, 2005).

$\mathrm{O}$ processo de desmatamento com a implantação de pastagens resulta em forte erosão, modificação do sistema de recarga, assoreamento dos rios e, por consequência incremento de metais nos cursos d'água, agravado por, segundo Thiollent \& Silva (2007), a área apresentar grande variação sazonal e com forte sedimentação episódica e deficiência hídrica na maior parte do ano.

Se objetiva com o presente estudo identificar qual a concentração dos metais cobalto (Co), cádmio $(\mathrm{Cd})$, cromo $(\mathrm{Cr})$, cobre $(\mathrm{Cu})$, níquel $(\mathrm{Ni})$, chumbo $(\mathrm{Pb})$, estrôncio $(\mathrm{Sr})$, vanádio $(\mathrm{V})$ e zinco (Zn) e qual a influência da geometria da rede de drenagem na dispersão e acumulação desses elementos.

\section{Geologia}

A área de estudo está localizada na Faixa Ribeira - Província Mantiqueira, em rochas de fácies anfibolito superior a granulito, apresentando uma estruturação preferencial NESW, cortada por falhas e fraturas de direção preferencial NW-SE. A Faixa Ribeira é composta por cinco terrenos tectonoestratigráfico separados por falhas de empurrão e/ou zonas de cisalhamento oblíquas transpressivas, sendo eles: Ocidental (Complexo Juiz de Fora e Andrelândia) e Oriental (Domínios Cambuci, Costeiro e Klippe Italva), Paraíba do Sul, Embu e Cabo Frio (Heilbron et al., 2004), onde os terrenos Ocidental e Oriental são separados um do outro por importante zona de cisalhamento (Moraes et al., 2004) o que condiciona alguns canais da região e a BHRSD, que está situada nos terrenos Ocidental e Oriental, sendo que o rio principal (São Domingos) está encaixado no contato entre esses dois terrenos.

As principais unidades que compõe o substrato da bacia são: Complexo Juiz de Fora e Andrelândia, no domínio Juiz de Fora - Terreno Ocidental e, Leucognaisses, Conjunto Metassedimentar e Complexo Serra da Bolívia no domínio Cambuci - Terreno Oriental.

O Complexo Juiz de Fora é composto por rochas com os minerais hiperstênio, biotita, hornblenda, quartzo e concentração variada de feldspato potássico e plagioclásio, sendo classificadas como enderbitos e charnockitos gnaissificados com presença de foliação milonítica, que devido à ausência de minerais micáceos apresenta alta resistência à erosão, em especial ao longo da bacia do rio São Domingos (Tupinambá et al., 2006).

O Grupo Andrelândia compreende gnaisses paraderivados de composição pelítica a semipelítica, compostos por granada, biotita, sillimanita, quartzo, plagioclásio e K-feldspato; como acessórios, ocorrem zircão, turmalina, rutilo e apatita; por vezes ortopiroxênio. Níveis métricos de quartzitos e gonditos, e lentes menores de rochas calciossilicáticas são comuns (Souza, 2011).

A unidade Leucognaisse é composta por rochas leucocráticas homogêneas, de composição granítica a granodiorítica, com biotita, piroxênio e anfibólio, por vezes apresenta enclaves de rochas máficas, hornblenda gnaisses bandados, granada gnaisses e rochas calciossilicáticas. Pode ser descrita como uma rocha quartzo-feldspática homogênea, geralmente muito alterada, com foliação marcante evidenciada por fitas de quartzo e feldspato resultante da milonitização (Tupinambá et al., 2006).

Por sua vez o Conjunto metassedimentar é formado por rochas leucocráticas, que têm como mineralogia básica: feldspato, quartzo e biotita, por vezes apresentando hornblenda e granada (Souza, 2011). Enquanto o Complexo Serra da Bolívia apresenta rochas leucocráticas, de composição feldspato, biotita, quartzo e, raramente, ortopiroxênio, com aspecto heterogêneo cortado por veios centimétricos de rocha granítica (quartzo-feldspática) e dique de diabásio.

O sistema de drenagem é composto por canais meandrantes a retilíneos, nos setores mais estruturados, favorecendo a exposição do substrato rochoso e esculpindo fortemente $\mathrm{o}$ relevo da região.

A geometria da rede de drenagem é treliça a sub-treliça, embora ocorram variações em alguns setores da bacia, com regiões mais segmentadas e com maior número de confluências predominando os canais de primeira ordem. Os canais de primeira e segunda ordem são pouco evidentes com baixa vazão e profundidade inferior a $1 \mathrm{~m}$, por vezes em processo de assoreamento (Souza, 2011), a bacia se caracteriza como de $4^{\mathrm{a}}$ ordem, onde apenas o canal principal apresenta setores com profundidades maiores, o que resulta em baixa energia de corrente. 


\section{MATERIAL E MÉTODO}

\section{Coleta}

Foram coletadas 59 amostras de sedimento nos canais com maior representatividade na bacia, sendo estes perenes, embora apresentem baixa vazão no período de estiagem.

Estes pontos de coleta foram distribuídos de modo a permitir ampla distribuição na bacia, assim como em áreas com forte estruturação (Figura 1), a amostragem foi realizada nos meses de setembro de 2006 (Pbx); agosto de 2009 e; julho de 2010 (SJU-x).

As amostras de sedimentos passaram por secagem em caixa de luz, pelo período de 48 horas, posteriormente passaram por seleção granulométrica para obtenção de amostras na fração 200 mesh $(0,074 \mathrm{~mm})$ - areia muito fina.

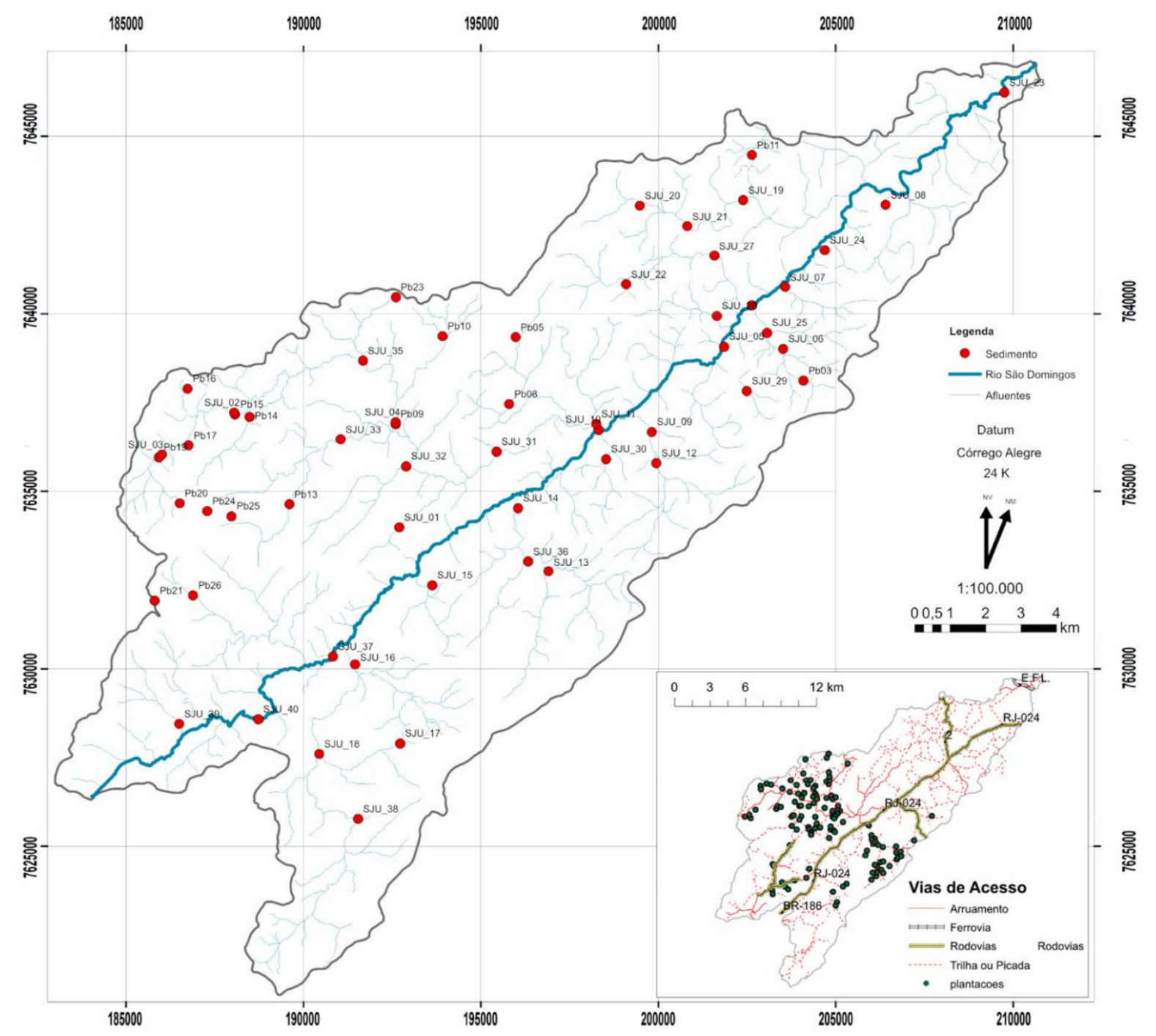

Figura 1 - Mapa de distribuição dos pontos de amostragem e localização das lavouras de tomate. Base Cartográfica: DRM-RJ.

\section{Análise Química}

As amostras foram analisadas em Inductive Coupled Plasma - Mass Spectrometry (ICP-MS) no Laboratório de Caracterização de Águas (LABAGUAS) da Pontifícia Universidade Católica do Rio de Janeiro (PUC-Rio) em equipamento $\operatorname{Varian}^{\circledR}$, modelo 820-MS, com interface de reação e colisão (CRI), equipado com um nebulizador 52 Micromist de baixa vazão conectado a uma câmara de nebulização Helix Cinnabar Fe/VG (Glass Expansion).

A análise se deu a partir da solução resultante do método de lixiviação da amostra que foi adaptado da normatização U.S. EPA SW6010, da Agência de Proteção Ambiental (EPA) dos Estados Unidos, o que implica em adicionar $10 \mathrm{ml}$ de uma solução de $\mathrm{HNO}_{3} \quad 0,1 \%$ (suprapuro) em $1 \mathrm{~g}$ de sedimento previamente pesado em tubo de polipropileno de $50 \mathrm{~mL}$ com tampa de rosca em balança com precisão de $0,0001 \mathrm{~g}$.

Em seguida, essa mistura foi colocada em um bloco digestor com temperatura ajustada a $80^{\circ} \mathrm{C}$ por 2 horas. Findo esse período, o material foi centrifugado a $2.000 \mathrm{rpm}$ por 10 minutos e o 
sobrenadante separado em outro tubo de polipropileno de $15 \mathrm{~mL}$ com tampa de rosca.

Para a determinação dos elementos de interesse por ICP-MS, foram realizadas diluições desta solução em $\mathrm{HNO}_{3} 1 \%$. Sendo obtidos dados de concentração dos metais $\mathrm{As}, \mathrm{Cd}, \mathrm{Co}, \mathrm{Cr}, \mathrm{Cu}, \mathrm{Ni}$, $\mathrm{Pb}, \mathrm{Sn}, \mathrm{Sr}, \mathrm{Ta}, \mathrm{V}, \mathrm{W}$ e $\mathrm{Zn}$.

Foram preparados três "brancos" na primeira bateria de análise (amostras $\mathrm{Pb}-\mathrm{x}$ ) e cinco "brancos" na segunda bateria (amostras SJU-x) que também foram utilizados para controle de qualidade do ambiente e soluções na preparação da amostra. Nos "brancos" as concentrações ficaram abaixo de $10^{-4} \mathrm{mg} . \mathrm{L}^{-1} \mathrm{em}$ todos os elementos.

Realizou-se a determinação dos elementos no modo quantitativo, utilizando uma curva contendo 9 pontos de calibração: 0,$5 ; 1,0 ; 2,0 ; 5,0 ; 10,0 ; 15,0$; 20,0; 40,0 e 50,0 $\mu \mathrm{g} . \mathrm{L}^{-1}$. A curva de calibração foi confeccionada a partir do padrão de calibração multielementares - Padrão ICP-MS 29 e 12 elementos (Perkin Elmer ${ }^{\circledR}$ ), mais padrão de Sn e Rh $\left(\right.$ Merck $\left.^{\circledR}\right)$.

Os limites de detecção são apresentados na tabela 1:

Tabela 1 - Limite de detecção.

\begin{tabular}{c|c|c|c|c|c|c|c|c|c|c|c|c}
\hline Elementos & $\mathrm{As}$ & $\mathrm{Cd}$ & $\mathrm{Co}$ & $\mathrm{Cr}$ & $\mathrm{Cu}$ & $\mathrm{Ni}$ & $\mathrm{Sn}$ & $\mathrm{Sr}$ & $\mathrm{Ta}$ & $\mathrm{V}$ & $\mathrm{W}$ & $\mathrm{Zn}$ \\
\hline $\begin{array}{c}\text { Amostras } \\
\text { Pbx }\end{array}$ & 0,005 & 0,00001 & 0,0003 & 0,0023 & 0,0269 & 0,0061 & 0,0001 & 0,0004 & 0,00001 & 0,0054 & 0,00001 & 0,0329 \\
\hline $\begin{array}{c}\text { Amostras } \\
\text { SJU-x }\end{array}$ & 0,005 & 0,00001 & 0,0001 & 0,006 & 0,001 & 0,0005 & 0,0001 & 0,0005 & 0,00001 & 0,002 & 0,00001 & 0,002 \\
\hline
\end{tabular}

Os elementos As, Sn, Ta e W apresentaram concentrações abaixo do limite de detecção em todas as amostras, razão pela qual não são utilizadas neste estudo.

A utilização da lixiviação permite analisar o material adsorvido na superfície do sedimento, portanto caracterizar as concentrações que foram incorporadas ao ambiente por processos exógenos e atividade antrópica.

\section{Geoprocessamento}

Foram confeccionados mapas topográficos a partir da base cartográfica disponibilizada pelo Instituto Brasileiro de Geografia e Estatística
(IBGE).

Estes mapas foram utilizados como base para a confecção das isolinhas de concentração de metais, bem como definir zonas homologas quanto a geometria da bacia e dos rios.

As isolinhas foram marcadas conforme a delimitação dos intervalos referentes às concentrações de metais com base nos respectivos histogramas e modas, a distribuição destas concentrações e a variação das curvas representada estão subdivididos em oito grupos (à exceção do $\mathrm{Cd}$ que foi dividido em cinco grupos devido a sua baixa concentração).

\section{RESULTADOS E DISCUSSÃO}

A região apresenta altos topográficos orientados na direção NE-SW, porém se observa um deslocamento da crista para NW. A folha topográfica onde está contida esta bacia apresenta lineamentos de orientação predominantemente NE-SW, que são concordantes com as zonas de sedimentação e a orientação preferencial dos canais maiores e de suas bacias. Apresenta bacia mais ampla e alongada com capturas de drenagem mais próximas das bordas, onde também se observa uma tendência ao alargamento.

Em relação a morfologia da bacia, se observa que esta pode ser compartimentada em quatro zoneamentos (Figura 2), que podem ser correlacionados à concentração dos metais. Essa estruturação afeta área de concentração e dispersão dos metais.

Os sedimentos analisados nos canais da bacia apresentam as concentrações de metais compreendidas em intervalos (Tabela 2) e distribuídas, segundo sua moda em 8 intervalos (Tabela 3).

Os elementos $\mathrm{Co}, \mathrm{Cr}, \mathrm{Cu}, \mathrm{Ni}, \mathrm{Pb}$ (Figura 3), $\mathrm{Sr}$ e $\mathrm{Zn}$, por analise dos mapas de drenagem e de concentrações, se concentram a montante e tendem a diminuir para jusante em toda área da bacia.

A zona 1 está contida em uma área restrita onde ocorre maior anomalia na geometria da bacia e apresenta concentrações de metais totais de intermediárias a alta (Tabela 4), a exceção de $\mathrm{Cu}$ que apresenta baixas concentrações. O comportamento dos metais pode estar relacionado a proximidade às suas fontes, principalmente se estas forem provenientes do substrato, por outro lado o comportamento de $\mathrm{Cu}$ pode estar ligado à sua alta mobilidade e dificuldade de fixação nos sedimentos (Goldschmidt, 1958), podendo resultar em maior transporte, assim como a baixa concentração desse elemento no substrato da bacia. 


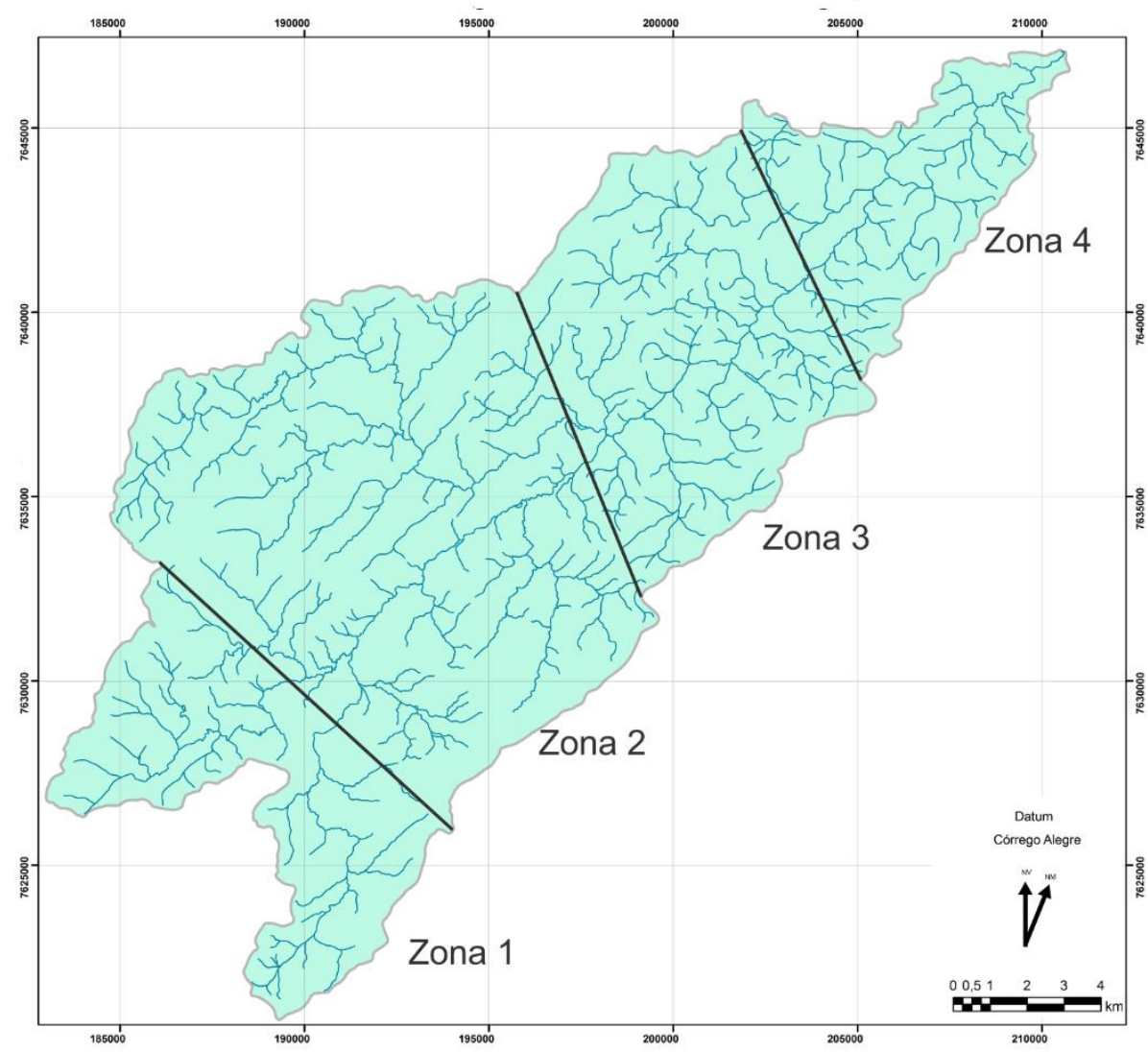

Figura 2 - Zoneamento definido com base na morfologia a bacia.

Tabela 2 - Concentrações máximas e mínimas dos elementos de interesse.

\begin{tabular}{c|c|c|c}
\hline Elemento & Mínimo $(\mathbf{m g} / \mathbf{k g})$ & Máximo $(\mathbf{m g} / \mathbf{k g})$ & Coef. de Variação \\
\hline Cádmio $(\mathrm{Cd})$ & $<$ L.D. & 0,026 & 1,480 \\
\hline Cobalto $(\mathrm{Co})$ & 0,146 & 2,247 & 0,593 \\
\hline Cobre $(\mathrm{Cu})$ & 0,007 & 2,245 & 0,529 \\
\hline Cromo $(\mathrm{Cr})$ & 0,019 & 0,835 & 0,523 \\
\hline Chumbo $(\mathrm{Pb})$ & 0,015 & 0,858 & 0,461 \\
\hline Estrôncio $(\mathrm{Sr})$ & 0,227 & 3,110 & 0,500 \\
\hline Níquel $(\mathrm{Ni})$ & 0,039 & 0,721 & 1,000 \\
\hline Vanádio $(\mathrm{V})$ & 0,002 & 1,000 & 0,488 \\
\hline Zinco $(\mathrm{Zn})$ & 0,209 & 9,599 & 1,801 \\
\hline
\end{tabular}

Arsênio (As) Estanho (Sn), Tântalo (Ta) e Tungstênio (W) - Concentrações inferiores ao background analítico. L.D. Limite de detecção

Tabela 3 - Distribuição das concentrações de metais segundo a moda.

\begin{tabular}{|c|c|c|c|c|c|c|c|c|}
\hline & \multicolumn{8}{|c|}{ Intervalos - mg/kg } \\
\hline Elemento & $1^{\circ}$ & $2^{\circ}$ & $3^{\circ}$ & $4^{\circ}$ & $5^{\circ}$ & $6^{\circ}$ & $7^{\circ}$ & $8^{\circ}$ \\
\hline $\begin{array}{l}\text { Cádmio } \\
\text { (Cd) }\end{array}$ & $<$ L.D. & $-0,001$ & $\begin{array}{c}0,001- \\
0,002\end{array}$ & $\begin{array}{c}0,002- \\
0,004\end{array}$ & $\begin{array}{c}0,004- \\
0,054\end{array}$ & - & - & - \\
\hline $\begin{array}{l}\text { Cobalto } \\
\text { (Co) }\end{array}$ & $\begin{array}{c}0,156- \\
0,375\end{array}$ & $\begin{array}{c}0,375- \\
0,609\end{array}$ & $\begin{array}{c}0,609- \\
0,803\end{array}$ & $\begin{array}{c}0,809- \\
1,001\end{array}$ & $\begin{array}{c}1,001- \\
1,190\end{array}$ & $\begin{array}{c}1,190- \\
1,371\end{array}$ & $\begin{array}{c}1,371- \\
1,550\end{array}$ & $\begin{array}{l}1,550- \\
2,238\end{array}$ \\
\hline Cobre $(\mathrm{Cu})$ & $\begin{array}{c}0,041- \\
0,301\end{array}$ & $\begin{array}{c}0,301- \\
0,569\end{array}$ & $\begin{array}{c}0,569- \\
0,715\end{array}$ & $\begin{array}{c}0,715- \\
0,824\end{array}$ & $\begin{array}{c}0,824- \\
0,951\end{array}$ & $\begin{array}{c}0,951- \\
1,143\end{array}$ & $\begin{array}{r}1,143- \\
1,544\end{array}$ & $\begin{array}{l}1,544- \\
2,244\end{array}$ \\
\hline Cromo $(\mathrm{Cr})$ & $\begin{array}{c}0,034- \\
0,055\end{array}$ & $\begin{array}{c}0,055- \\
0,125\end{array}$ & $\begin{array}{c}0,125- \\
0,166\end{array}$ & $\begin{array}{c}0,166- \\
0,223\end{array}$ & $\begin{array}{c}0,223- \\
0,261\end{array}$ & $\begin{array}{c}0,261- \\
0,325\end{array}$ & $\begin{array}{c}0,325- \\
0,426\end{array}$ & $\begin{array}{c}0,426- \\
0,835\end{array}$ \\
\hline $\begin{array}{c}\text { Chumbo } \\
(\mathrm{Pb})\end{array}$ & $0,54-0,180$ & $\begin{array}{c}0,180- \\
0,258\end{array}$ & $\begin{array}{c}0,258- \\
0,305\end{array}$ & $\begin{array}{c}0,305- \\
0,380\end{array}$ & $\begin{array}{c}0,380- \\
0,473\end{array}$ & $\begin{array}{c}0,473- \\
0,555\end{array}$ & $\begin{array}{c}0,555- \\
0,700\end{array}$ & $\begin{array}{c}0,700- \\
0,859\end{array}$ \\
\hline $\begin{array}{c}\text { Estrôncio } \\
\text { (Sr) }\end{array}$ & $\begin{array}{c}0,220- \\
0,317\end{array}$ & $\begin{array}{c}0,317- \\
0,656\end{array}$ & $\begin{array}{c}0,656- \\
0,844\end{array}$ & $\begin{array}{c}0,844- \\
1,056\end{array}$ & $\begin{array}{c}1,056- \\
1,276\end{array}$ & $\begin{array}{c}1,276- \\
1,462\end{array}$ & $\begin{array}{c}1,462- \\
1,900\end{array}$ & $\begin{array}{l}1,900- \\
3,100\end{array}$ \\
\hline Níquel (Ni) & $\begin{array}{c}0,041- \\
0,086\end{array}$ & $\begin{array}{c}0,086- \\
0,188\end{array}$ & $\begin{array}{c}0,188- \\
0,262\end{array}$ & $\begin{array}{c}0,262- \\
0,335\end{array}$ & $\begin{array}{c}0,335- \\
0,375\end{array}$ & $\begin{array}{c}0,375- \\
0,436\end{array}$ & $\begin{array}{c}0,436- \\
0,545\end{array}$ & $\begin{array}{c}0,545- \\
0,721\end{array}$ \\
\hline Vanádio (V) & $\begin{array}{c}0,003- \\
0,018\end{array}$ & $\begin{array}{c}0,018- \\
0,040\end{array}$ & $\begin{array}{c}0,400- \\
0,066\end{array}$ & $\begin{array}{c}0,066- \\
0,096\end{array}$ & $\begin{array}{c}0,096- \\
0,122\end{array}$ & $\begin{array}{c}0,122- \\
0,172\end{array}$ & $\begin{array}{c}0,172- \\
0,451\end{array}$ & $\begin{array}{c}0,451- \\
0,674\end{array}$ \\
\hline Zinco (Zn) & $\begin{array}{c}0,247- \\
0,309\end{array}$ & $\begin{array}{c}0,309- \\
0,478\end{array}$ & $\begin{array}{c}0,478- \\
0,656\end{array}$ & $\begin{array}{c}0,656- \\
0,835\end{array}$ & $\begin{array}{c}0,835- \\
1,053\end{array}$ & $\begin{array}{c}1,053- \\
1,357\end{array}$ & $\begin{array}{c}1,357- \\
1,772\end{array}$ & $\begin{array}{c}1,772- \\
9,599\end{array}$ \\
\hline
\end{tabular}

L.D. = Limite de detecção 


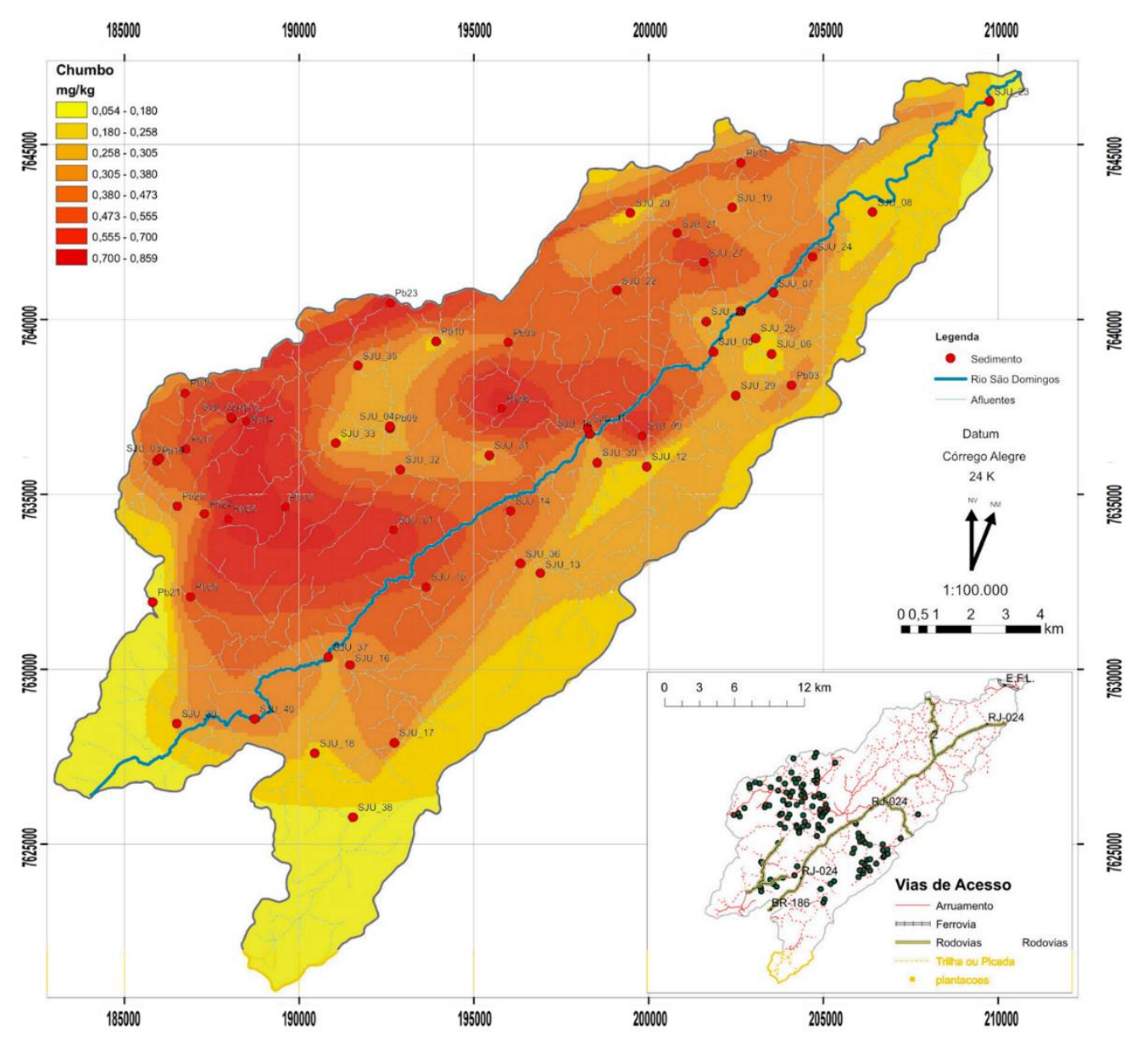

Figura 3 - Distribuição das concentrações de chumbo ao longo da bacia.

A zona 2 apresenta as maiores concentrações de elementos e maior amplitude dessas concentrações, sendo esta uma zona amplamente estruturada, com maior anomalia de drenagem, diversas capturas de drenagem e padrão treliça. Além disso, é uma área com ocorrência de protominério de manganês (gondito) que apresenta natural enriquecimento em diversos metais. A conjunção desses dois fatores, morfologia que favorece um sistema de trapeamento e, litologia enriquecida, pode ser responsável por caracterizar esta área como a mais enriquecida em metais da bacia. Também se destaca nesta área uma grande incidência de plantio de tomate caracterizado pela monocultura e uso ostensivo de agrotóxico.A zona 3 apresenta drenagem com padrão dendrítico a sub-treliça, se caracteriza por apresentar concentrações e abrangência intermediárias a baixa, embora se apresente a jusante da zona mais enriquecida. Esse aspecto pode ser relacionado a dois fatores essenciais: (i) ao trapeamento dos metais na zona 2 controlado pela grande estruturação do setor; (ii) ou ao tempo de migração condicionando a dispersão dos mesmos, que podem acontecer de forma diferenciado conforme as espécies químicas que formam.

Tabela 4 - Concentração de elementos e sua predominância por zoneamento morfológico.

\begin{tabular}{c|c|c|c|c}
\hline Elementos & Zona 1 & Zona 2 & Zona 3 & Zona 4 \\
\hline Cádmio $(\mathrm{Cd})$ & Alta & Intermediária & Baixa & Intermediária \\
\hline Cobalto $(\mathrm{Co})$ & Intermediária & Alta & Baixa & Intermediária \\
\hline Cobre $(\mathrm{Cu})$ & Baixa & Alta & Baixa & Intermediária \\
\hline Cromo $(\mathrm{Cr})$ & Intermediária & Alta & Baixa & Intermediária \\
\hline Chumbo $(\mathrm{Pb})$ & Intermediária & Alta & Intermediária & Baixa \\
\hline Estrôncio $(\mathrm{Sr})$ & Alta & Alta & Intermediária & Baixa \\
\hline Níquel $(\mathrm{Ni})$ & Intermediária & Alta & Baixa & Intermediária \\
\hline Vanádio $(\mathrm{V})$ & Intermediária & Alta & Baixa & Alta \\
\hline Zinco $(\mathrm{Zn})$ & Intermediária & Alta & Baixa & Intermediária \\
\hline
\end{tabular}

Alta $=$ Predominância dos intervalos $7^{\circ}$ e $8^{\circ}$; Intermediária $=$ Predominância dos intervalos $4^{\circ}, 5^{\circ}$ e $6^{\circ} ;$ Baixa $=$ Predominância dos intervalos $1^{\circ}, 2^{\circ}$ e $3^{\circ}$. 
Por fim a zona 4 apresenta-se como uma área com menor anomalia de drenagem, sendo essa a zona de confluência com o rio Muriaé, podendo representar um região de interferência, onde em período de extravasamento do rio Muriaé, essa área se caracterizaria como uma área de retenção, enquanto em um regime de vazão normal, seria uma área de maior energia, resultando em um sistema de maior acúmulo dos elementos de menor mobilidade e dispersão dos elementos mais móveis, mas o que se observa é que tanto elementos de baixa e alta mobilidade apresentam concentrações intermediárias. Também dever-se considerar que, caso a fontes dos elementos sejam de rochas a montante, parte desses elementos ficariam retidos nas trapas identificadas na zona 2.

Souza et al. (2017) e Souza (2011) identificaram fontes de origem antrópica e natural influenciado a composição dos sedimentos da bacia, onde Souza (2011) identificou cinco fontes contribuintes de metais na área desta bacia, através do uso de assinatura isotópica ${ }^{206} \mathrm{~Pb} /{ }^{207} \mathrm{~Pb}$, caracterizados como: dois intervalos de maior contribuição antrópicas e três como misturas de rochas do embasamento.

Por correlação aos dados obtidos pelos autores, a zona 1 apresenta duas fontes de origem antrópicas e duas de origem natural, enquanto na zona 2 e 3 são observadas assinaturas das cinco fontes de Souza (2011), ao passo que na zona 4 apenas duas fontes, ambas de origem natural. Embora a assinatura das cinco fontes se distribua ao longo de toda bacia, as assinaturas de origem antrópica se distribuem, preferencialmente, na zona 2 e, parcialmente na zona 3.

Com base na composição e afinidade geoquímica e possíveis inclusões no retículo dos minerais, caracterizando impurezas, é possível inferir quais as fontes de metais naturais na área da bacia, portanto se presume que os minerais das rochas do Domínio Juiz de Fora os minerais, podem contribuir com as concentrações naturais dos seguintes metais na área da bacia: apatita $(\mathrm{Pb}$ e $\mathrm{Sr}$ ); biotita (Co, $\mathrm{Cu}, \mathrm{Cd}, \mathrm{Ni}, \mathrm{Sr}, \mathrm{V}$ e $\mathrm{Zn}$ ); granada $(\mathrm{Cu}$ e $\mathrm{Sr})$; hornblenda $(\mathrm{Pb}, \mathrm{Cr}, \mathrm{Co}, \mathrm{Cu}$, $\mathrm{Ni}, \mathrm{Sr}, \mathrm{V}$ e $\mathrm{Zn})$; ortoclásio (Pb e $\mathrm{Sr})$; epidoto $(\mathrm{Cr}$, $\mathrm{Pb}$ e $\mathrm{Sr}$ ); piroxênio $(\mathrm{Pb}, \mathrm{Cr}, \mathrm{Co}, \mathrm{Sr}$ e $\mathrm{V})$; plagioclásio $(\mathrm{Cu}$ e $\mathrm{Sr})$; rutilo $(\mathrm{Cr}$ e $\mathrm{V})$; titanita (Co, Ni, Sr, V e Zn) e; zircão (Pb).

A maior susceptibilidade à alteração e abundância de cada um destes minerais determinará a amplitude de sua contribuição. $\mathrm{O}$ zircão, por ser um resistato (minerais resistentes ao intemperismo), não irá perder elementos durante o intemperismo, ao contrário dos minerais diopsídio, que contribuirá com $\mathrm{Cr}$ e, hiperstênio com $\mathrm{Pb}, \mathrm{Co}$, $\mathrm{Sr}$ e V por se alterarem facilmente. Alguns minerais sulfetados, principalmente aqueles resultantes do processo de hidrotermal presente na área da bacia, contribuirão com as concentrações de $\mathrm{Pb}, \mathrm{Cu}$, $\mathrm{Co}, \mathrm{Cd}, \mathrm{Ni}, \mathrm{V}$ e $\mathrm{Zn}$.

No Domínio Cambuci os minerais que fazem parte da composição das unidades podem contribuir com as concentrações naturais dos metais: biotita ( $\mathrm{Co}, \mathrm{Cu}, \mathrm{Cd}, \mathrm{Ni}, \mathrm{Sr}, \mathrm{V}$ e $\mathrm{Zn}$ ); granada $(\mathrm{Cu}$ e $\mathrm{Sr})$; hornblenda $(\mathrm{Pb}, \mathrm{Cr}, \mathrm{Co}, \mathrm{Cu}$, $\mathrm{Ni}, \mathrm{Sr}, \mathrm{V}$ e $\mathrm{Zn}$ ); ortoclásio e microclina (Pb e $\mathrm{Sr}$ ); piroxênio $(\mathrm{Pb}, \mathrm{Cr}, \mathrm{Co}, \mathrm{Sr}$ e V); plagioclásio $(\mathrm{Cu}$ e $\mathrm{Sr})$ e; zircão $(\mathrm{Pb})$. Do mármore dolomítico, especificamente, a contribuição será de forsterita - olivina magnesiana $(\mathrm{Co}, \mathrm{Cu}, \mathrm{Cr}$ e $\mathrm{Ni})$ e dolomita (Co, Ni e Zn).

Embora nenhum mineral com altos teores de metais pesados tenha sido observado, esses elementos se encontram instáveis na estrutura de minerais como: anfibólio, piroxênio, apatita, titanita e epidoto (Pereira, 2012).

As afinidades geoquímicas geralmente se apresentam da seguinte forma $\mathrm{Cr}=\mathrm{Pb}>\mathrm{Cu}>\mathrm{Zn}>\mathrm{Ni}>\mathrm{Cd} \quad$ (Pereira, 2012). No entanto, na área de bacia o que se observa é correlação de $\mathrm{Sr}>\mathrm{Co}>\mathrm{Zn}=\mathrm{Cu}$ e $\mathrm{Pb}>\mathrm{Ni}=\mathrm{Cr}>\mathrm{Cd}=\mathrm{V}$. Essa relação se mantém nas análises em que são representados valores aberrantes (outliers), havendo sutil diferenciação na afinidade do $\mathrm{Sr}$.

Sendo elementos, como $\mathrm{Ni}, \mathrm{Pb}$ e $\mathrm{Cd}$, praticamente insolúveis em condições de $\mathrm{pH}$ e Eh registradas nos rios (Carvalho, 1995) e com tendência a formar minerais densos, essas concentrações deveriam se restringir a ambientes próximos a fonte. Entretanto Pereira (2012) afirma que em água subterrâneas o $\mathrm{Pb}$, assim como o $\mathrm{Cu}$ e $\mathrm{Zn}$, são facilmente solubilizados e carreados, o que favorece sua dispersão em sub-superfície. Estes elementos serão, posteriormente, adsorvidos ou precipitados se atingirem condições de Eh e pH favoráveis. $\mathrm{O}$ mesmo pode ocorrer quando cessar o transporte. Parte desse comportamento se deve a sua característica calcófila (afinidade ao enxofre - S), formando composto de sulfeto, facilmente solubilizados e, atingindo condições de superfície, será precipitado nas frações mais finas nos canais. 
Uma vez que as concentrações estão associadas, preferencialmente, a diversas misturas das rochas do embasamento, pode-se assumir que a captura de drenagem, anomalia de bacia e erosão dos setores mais estruturados (Zonas 1 e 2), associados a presença do gondito na zona 2, é o fator controlador desta concentração e dispersão, resultando em zonas de trapeamento que irão reter parte dos metais disponíveis na bacia. A zona 1 também pode ter influência da matéria orgânica proveniente do setor de vegetação mais preservada na bacia, restrita a borda SW da bacia, onde a matéria orgânica retém a maior parte dos metais devido a sua alta capacidade de adsorção.
Outro fator que favorecer a concentração de metais é a fração do sedimento disponível, contudo existe pouca variedade textural dos sedimentos dos canais, salvo o rio principal (São Domingos), o que favoreceria um maior transporte em solução dos metais analisados, favorecido pela estruturação da rede de drenagem.

Outros aspectos contribuem para a dispersão dos elementos, como o solo e as especiações químicas, onde alguns comportamentos podem ser analisados pela observação diagrama de Cluster (Figura 4). Neste diagrama se observa que $\mathrm{Cu}, \mathrm{Co}, \mathrm{Sr}$ e $\mathrm{Zn}$ formam um grupo de similaridade, enquanto $\mathrm{Cd}, \mathrm{Cr}, \mathrm{Ni}, \mathrm{Pb}$ e $\mathrm{V}$ forma outro grupo.

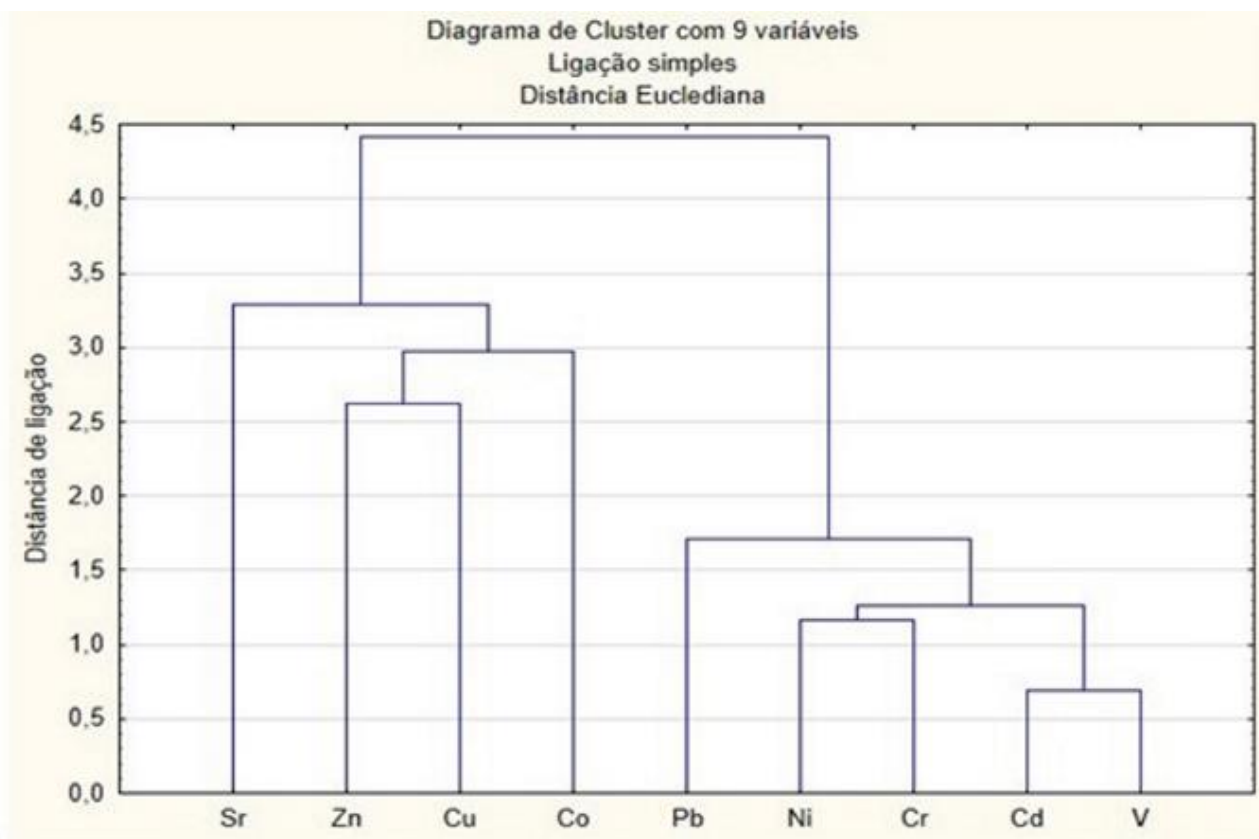

Figura 4 - Dendograma da relação entre os elementos químicos analisados no BHRSD.

Em vias de regra $\mathrm{Cu}, \mathrm{Pb}$ e $\mathrm{Zn}$ são elementos que tem afinidade química, de forma que caminham juntos nos processos exógenos, embora sua mobilidade esteja relacionada a estabilidade química do mineral no qual estejam contidos (Pereira, 2012). A relação de $\mathrm{Pb}$ que não formam fases minerais afins, sugere contribuições que sejam provenientes de fontes distintas do embasamento, tal como atividades antrópicas.

O cádmio, normalmente, forma complexos estáveis, o que justifica as baixas concentrações encontradas, quando consideramos que essas concentrações são de origem natural. Segundo Goldschmidt (1958), é um elemento que tem forte afinidade com o $\mathrm{S}$ e, assim como $\mathrm{Zn}$, se precipita em soluções muito ácidas, podendo se concentrar em serrapilheira. Portanto é possível que a presença de matéria orgânica em períodos e locais de maior estagnação favoreça a formação de ácidos húmicos e com isso diminuam o $\mathrm{pH}$ da água, consequentemente, resultando em maior precipitação do $\mathrm{Cd}$, que já tem baixa concentração nesse tipo de ambiente.

Por sua vez o $\mathrm{Sr}$ pode estar relacionado a salinização do solo, comum na região, cuja fonte mais provável seja de minerais magnesianos, uma vez que $\mathrm{Mg}$ e $\mathrm{Sr}$ possuem afinidade geoquímica. O Sr também tende a se acumular em depósitos sedimentares de dióxido de Mn, indicando estar associado a intemperização do gondito. Supõe-se que sua concentração estaria associada a minerais de fração mais grossa, resultando em maior proximidade com a área fonte (Wasserman \& Wasserman, 2008).

A utilização de produtos químicos no tratamento de solo para agricultura, tais como, cal (hidróxido de cálcio) e calcário (carbonato de 
cálcio) pode favorecer a formação de complexos enriquecidos em $\mathrm{Sr}$ por substituição iônica que se fixam no solo, inviabilizando o transporte para os canais e assim diminuindo a concentração de $\mathrm{Sr}$ nas drenagens em áreas de intenso cultivo.

Pressupõe-se que em dolomitos as concentrações de $\mathrm{Sr}$ são muito baixas, na maioria dos casos, isso se deve, segundo Goldschmidt (1958) ao processo de dolomitização de carbonatos por soluções contendo sais de magnésio, no qual o processo substitui pelo $\mathrm{Mg}$ o $\mathrm{Ca}$ da rocha original e, no caso do Sr, devido ao seu raio iônico, este será mais facilmente substituído pelo $\mathrm{Mg}$, esse fato justifica as concentrações de $\mathrm{Sr}$ na zona 4 , onde existe como fonte um litotipo de mármore. Assim como o $\mathrm{Sr}$, a aplicação de produtos químicos como cal e flúor pode fixar o $\mathrm{V}$ junto a fosfatos em minerais secundários de apatita. No entanto ainda assim a maior parte do $\mathrm{V}$ é removida durante o intemperismo, onde vanadatos solúveis podem viajar em solução.

A precipitação do $\mathrm{V}$ menos solúvel se dá pela presença de agentes redutores, tais como matéria orgânica e concentração local de cátions de metais pesados que formam componentes insolúveis com ânions de V. O fenômeno mais importante durante o intemperismo dos compostos de $\mathrm{V}$ é a oxidação para íons de vanadato, esses íons são imóveis devido a precipitação (Goldschmidt, 1958). Dessa forma a concentração de $\mathrm{V}$ em sedimentos de corrente é bastante limitada, este se manterá na rocha fonte, em horizontes ferruginosos no solo e concreções ou estará solubilizado na água, não ocasionando sua deposição.

Existem concentrações de $\mathrm{Pb}$ em áreas com alta densidade de plantação, o que possibilita a incorporação de metais aos cursos d'água devido a aplicação nas plantações de tomate de produtos químicos.

Comparativamente podemos citar que Santos (2006) encontrou fertilizantes utilizados na área da bacia com altas concentrações de radioelementos. Montogmery (2008) também indica que $\mathrm{As}, \mathrm{Cd}, \mathrm{Cr}, \mathrm{Cu}, \mathrm{Hg}, \mathrm{Mn}, \mathrm{Ni}, \mathrm{Pb}$ e $\mathrm{Zn}$ estão associados a contaminação por fertilizantes, reforçando a possível contribuição de agrotóxicos na concentração dos metais.

No entanto, os agrotóxicos não são responsáveis pelas maiores concentrações na BHRSD, uma vez que estas estão a montante dessas lavouras e diminuem gradativamente a jusante, parte devido a própria dinâmica de dispersão dos rios, parte devido a geometria dos canais.

Esta geometria contribui para a acumulação destes metais uma vez que, associada ao processo de assoreamento intenso na região, diminui o regime de fluxo local e favorece a sedimentação. Sendo assim, as concentrações tendem a se manter mais próximas da fonte.

Além da geometria do canal, a baixa energia do ambiente favorece a deposição de metais, assim como a decantação de partículas mais finas que possuem maior poder de adsorção. Essas partículas têm, segundo Wasserman \& Wasserman (2008), maior reatividade na superfície e maior capacidade de interação com substâncias dissolvidas.

Em relação ao $\mathrm{Cu}$, quando bivalente se combina com vários ânions, sendo assim o processo de oxidação, lixiviação e reprecipitação não apenas resulta em cimentação em depósitos, imediatamente, abaixo da zona de oxidação, mas também migra sob forma de soluções de $\mathrm{Cu}$ e outros metais (Goldschmidt, 1958), isso justifica o $\mathrm{Cu}$ muito reduzido em resíduo sedimentares de algumas áreas da bacia. Porém o $\mathrm{Cu}$ pode ser encontrado em inseticida e fungicida, resultando num incremento de $\mathrm{Cu}$ no solo.

Ainda segundo Goldschmidt (1958) sulfetos de $\mathrm{Zn}$ possuem uma incomum capacidade de capturar outros metais. Um dos principais minerais de $\mathrm{Zn}$ (esfalerita) pode conter os elementos $\mathrm{Co}, \mathrm{Cu}$ e $\mathrm{Cd}$, visto que ocorre mútua substituição de Zn e Co em óxidos e sulfetos, de $\mathrm{Zn}$ e Cd. Portanto uma vez que estes elementos apresentam o mesmo comportamento de dispersão, pode-se associar que esses elementos são provenientes, principalmente, de sulfetos.

Outro fator que favorece essa associação reside no fato de que o $\mathrm{Pb}$ e $\mathrm{Zn}$ quando em silicatos e óxidos formam complexos imóveis. Sendo assim, além da presença dos metais em si (considerando que estão associados aos sulfetos), a presença de $\mathrm{S}$ pode apresentar, em algum nível, uma influência no ambiente da bacia.

Mesmo que as concentrações sejam pequenas, Luoma \& Rainbow (2008) afirmam que a contaminação em sedimentos de granulometria fina terá maior implicações biológicas, pois as concentrações obtidas representam as concentrações de metais biodisponíveis que são adsorvidos nas partículas menores que 200 mesh e, ainda que as concentrações sejam pequenas, estão disponíveis para serem absorvidos por seres vivos. 


\section{CONCLUSÕES}

Observa-se que as concentrações de metais adsorvidos nos sedimentos dos canais da bacia com contribuição de rochas do embasamento, que é mais fortemente percebida nas áreas com maior estruturação, capturas de drenagem e anomalia de bacia, indicando ser este um importante agente de dispersão geoquímica.

As afinidades geoquímicas são controladas pelas especiações químicas associadas às interações com os componentes da bacia como solo, agricultura e água.

Os metais são trapeados junto à área mais estruturada da bacia, excetua-se o $\mathrm{Cd}$, devido a sua baixa mobilidade, tornando dificultosa sua liberação nos cursos d'água e, uma vez ocorrendo, é confinando junto às cabeceiras.

As fontes de metais para o sistema de drenagem da bacia se sobrepõem, e são diferentes em cada área, como muito do que foi analisado é proveniente da erosão dos corpos geológicos, não se pode afirmar que a bacia está contaminada por metais sob o ponto de vista legal.

Não há concentrações elevadas de metais no sedimento de corrente, embora se possa afirmar que há influência antrópica.

\section{AGRADECIMENTOS}

Os autores agradecem ao M.Sc David Rocha e a geóloga Sofia Corrêa pelo apoio ao campo e coleta de amostras. Igualmente agradecemos a Dr. ${ }^{a}$ Carla Semiramis Silveira pelas contribuições.

\section{REFERÊNCIAS}

CARVAlho, N.O. Hidrossedimentologia Prática. Rio de Janeiro: CPRM., 372 p., 1994

DANTAS, M.E.; SHINZATO, E.; MEDINA, A.I.M.; SILVA, C.R.; PIMENTEL, J.; LUMBRERAS, J.F.; CALDERANO, S.B.; CARVALHO FILHO, A. Diagnóstico Geoambiental do Estado do Rio de Janeiro, CPRM. 2005. In: OFICINA INTERNACIONAL DE ORDENAMENTO TERRITORIAL MINEIRO - CYTED (Ciencia y Tecnologia para el Desarollo Cooperacion IberoAmericana), v. 1, 2005.

FIDALGO, E.C.C. \& ABREU, M.B. Uso de imagens ASTER para o mapeamento do uso e cobertura da terra na bacia hidrográfica do rio São Domingos, RJ. 2005. In: SIMPÓSIO BRASILEIRO DE SENSORIAMENTO REMOTO, XII. Goiânia, Brasil. Anais...Goiania: INPE, 2005, p. 3747-3753.

GOLDSCHMIDT, V.M. Geochemistry. Oxford University Press. Oslo. 730 p., 1958.

HEILBRON, M.; PEDROSA-SOARES, A.C.; NETO, M.C.C.; SILVA, L.C.; TROW, R.A.J.; JANASI, V.A. Província Mantiqueira In: NETO, V.M., BARTORELLI, A., CARNEIRO, C.D.R., NEVES, B.B.B. Geologia do Continente Sul-Americano - Evolução da Obra de Fernando Flávio Marques de Almeida. Brasília: UNESCO. 2004

LUOMA, S. \& RAINBOW, P.S. Metal contamination in aquatic environments. Science and lateral management. New York: Ed. Cambridge, 573 p., 2008.

MONTOGOMERY, C.W. Environmental Geology. Columbus: Mc Graw-Hill. 8. ed. 556 p., 2008.

MORAES, R.; FUCK, R.A.; DUARTE, B.P.; BARBOSA, J.S.F.; LEITE, C.M.M. Granulitos do Brasil In: NETO, V.M., BARTORELLI, A., CARNEIRO, C.D.R., NEVES, B.B.B. Geologia do Continente Sul-Americano - Evolução da Obra de Fernando Flávio Marques de Almeida. Brasília: UNESCO. p. 292-321. 2004.

PEREIRA, R.M. Fundamentos de prospecção mineral. $2^{\mathrm{a}}$ ed. Rio de Janeiro: Interciência. 167 p., 2012.

SANTO, A.C.L. Gamaespectrometria Aplicada ao Estudo de Áreas Agrícolas. Brasília. 2007. Dissertação (Mestrado em Geociências), Instituto de Geociências, Universidade de Brasília, Brasília.
SOUZA, A.M. Caracterização Ambiental da Bacia Hidrográfica do Rio São Domingos a Partir da Análise Geoquímica e Isotópica Pb/Pb. Rio de Janeiro. 2011. 108 p. Dissertação (Mestrado em Geologia) - Faculdade de Geologia - Universidade do Estado do Rio de Janeiro.

SOUZA, A.M. GERALDES, M.C. SANTOS, A.C. Assessment of anthropic sources through pb isotopes in São Domingos basin, Rio de Janeiro, Brazil Journal of Sedimentary Environments. v. 2, n. 2. p. 99-110, 2017.

SPADOTTO, C.A.; FILIZOLA, H.; GOMES, M.A.F. Avaliação do Potencial de Lixiviação de Pesticidas em Latossolo da Região de Guaíra, SP. Pesticidas: Revista Ecotoxicol e Meio Ambiente, Curitiba, v. 11, 2001

THIOLLENT, M. \& SILVA, G.O. Metodologia de pesquisa-ação na área de gestão de problemas ambientais. Reciis Revista Eletrônica de Comunicação, Informação \& Inovação em Saúde, Rio de Janeiro, v. 1, n. 1. p. 93-100, 2007.

TUPINAMBÁ, M.; HEILBRON, M.; ALMEIDA, J.; DUARTE, B.; NOGUEIRA, J.R.; ALMEIDA, C.G.; MIRANDA, A.; MEDEIROS, F.; MANSUR, K. Base Geológica da Bacia do Rio São Domingos, Itaperuna (RJ): Metodologia e Resultados. In: WORKSHOP DE INTEGRAÇÃO DE INFORMAÇÕES OBTIDAS NO ÂMBITO DO PROJETO PRODETAB AQÜÍFEROS, 2006.

VILLELA, S. M. \& MATTOS, A. Hidrologia Aplicada. São Paulo. Ed. McGraw-Hill do Brasil. 245p., 1975.

WASSERMAN, J.C. \& WASSERMAN, M.A. Comportamento de metais em sedimentos In: NETO, J.A.B.; WALLNERKERSANACH, M. P. (Org.) Poluição Marinha. Rio de Janeiro: Ed. Interciência. 412 p., 2008.

Recebido em 24 de março de 2019 Aceito em 06 de dezembro de 2019 